\title{
Differentiating between hospitals according to the "maturity" of quality improvement systems: a new classification scheme in a sample of European hospitals
}

\author{
M J M H Lombarts, I Rupp, ${ }^{1}$ P Vallejo, ${ }^{2}$ N S Klazinga, ${ }^{1}$ R Suñol ${ }^{2}$
}

${ }^{1}$ Academic Medical Center, Department of Social Medicine, University of Amsterdam, Amsterdam, the Netherlands; ${ }^{2}$ Avedis Donabedian Institute, Autonomous University of Barcelona, Barcelona, Spain

Correspondence to: Dr M J M H (Kiki) Lombarts, Academic Medical Center, Department of Social Medicine, University of Amsterdam,

Meibergdreef 9, P.0. Box 22700 1100 DE Amsterdam, the Netherlands; M.J.Lombarts@ amc.uva.nl

Accepted 23 November 2008

\begin{abstract}
Aim: This study, part of the Methods of Assessing Response to Quality Improvement Strategies (MARQuIS) research project focusing on cross-border patients in Europe, investigated quality policies and improvement in healthcare systems across the European Union (EU). The aim was to develop a classification scheme for the level of quality improvement (maturity) in EU hospitals, in order to evaluate hospitals according to the maturity of their quality improvement activities.
\end{abstract}

Methods: A web-based questionnaire survey designed to measure quality improvement in EU hospitals was used as the basis for the classification scheme. Items included for the development of an evaluation tool-the maturity index-were considered important contributors to quality improvement. The four-stage quality cycle (plan, do, check and act) was used to determine the level of maturity of the various items. Psychometric properties of the classification scheme were assessed, and validation analyses were performed.

Results: A total of 389 hospitals participated in a questionnaire survey; response rates varied by country. For a final sample of 349 hospitals, it was possible to construct a quality improvement maturity index which consisted of seven domains and 113 items. The results of independent analyses sustained the validity of the index, which was useful in differentiating between hospitals in the research sample according to the maturity of their quality improvement system (defined as the total of all quality improvement activities).

Discussion: Further research is recommended to develop an instrument which for use in the future as a practical tool to evaluate the maturity of hospital quality improvement systems.

The acid test for any quality improvement (OI) system is its impact on the quality of patient care. Measuring such impact reliably, however, is difficult, and studies presenting significant measurable gains that can be attributed to hospital-wide OI systems are rare. Most studies have reported what hospitals actually do to assure and improve quality. Over the past two decades, several projects at the European level have set out to characterise quality assurance and OI activities in hospitals. The Concerted Action Programme on Quality Assurance in Hospitals (COMAC/HSR/OA), carried out in 1990-3 in 15 European countries, was one of the first to report on the application of quality assurance methods in European hospitals. ${ }^{1}$ As a follow-up, the European Union (EU) funded the 4-year ExPeRT project beginning in 1996 which shifted the focus to mechanisms of external assessment, catalogued the range of programmes offering external evaluation, and described their use in assessing and implementing OI systems. ${ }^{2}$ Because no concise, comprehensive measures are available as a gold standard for OI implementation, more recent studies have tried to define developmental stages of $\mathrm{OI}$ systems, for either external comparative reasons or for hospital self-assessment. ${ }^{3-5}$ In the Methods of Assessing Response to Quality Improvement Strategies (MARQuIS) study we aimed at moving to the next level of analysis, and tried to evaluate the impact of hospital-wide OI strategies on quality activities and outputs, since this has not been done in previous research at the European level. To facilitate our analysis we developed a classification model based on the maturity of hospital OI systems, defined as the total set of OI activities performed. This classification model was named the quality improvement maturity index. Its design and application to the classification hospitals in our research sample are the focus of this article.

This study was conducted as part of the MARQuIS project, funded as part of the Scientific Support to Policies component of the EU 6th Framework Research Programme. The MARQuIS project aims to investigate and compare different QI policies and strategies in healthcare systems across the 25 member states of the EU, and to consider their potential use when patients cross borders to receive healthcare.

\section{METHODS}

Design of the questionnaire on quality improvement strategies

We conducted a web-based questionnaire survey among acute care hospitals in eight EU member states. ${ }^{6}$ The questionnaire measured OI, defined as the application of quality policies and procedures, quality governance structures, and quality activities to close the gap between current and expected levels of quality. Items for inclusion were selected on the basis of internationally accepted evaluations as contributors to OI. Several sources were consulted, such as existing OI questionnaires, ${ }^{37-11}$ a review of the quality literature ${ }^{11-13}$ an analysis of accreditation manuals, ${ }^{14}{ }^{15}$ and the results of previous MARQuIS studies, including a literature review covering $\mathrm{OI}$ strategies in $\mathrm{EU}$ member 
Table 1 Principles for coding and recoding items in the quality improvement (0I) maturity index

\begin{tabular}{|c|c|c|c|}
\hline \multicolumn{4}{|c|}{ Stage of quality improvement maturity level } \\
\hline 1 (Most mature) & 2 & 3 & 4 (Least mature) \\
\hline External assessment & Written reports of activities & Policies & No \\
\hline Internal audits & Implementation of quality and safety activities, ie: & Ol plans & \\
\hline Professionals formally approve policies & - Periodic and systematic evaluation of data collected in laboratories & Strategies & \\
\hline Accountability & - Regular calibration or maintenance equipment & Staff responsibility for 0 l activities & \\
\hline Feedback to staff and board & - Internal budget for $\mathrm{Ol}$ & Quality or safety teams or committees & \\
\hline Review and use of indicator data & & & \\
\hline
\end{tabular}

states. $^{16-18}$ The questionnaire consisted of four sections: one focused on $\mathrm{OI}$ at the hospital-wide level, and the other three dealt with specific medical conditions. These conditions were selected based on two criteria: the condition had to represent a significant volume of cross-border patient care, ${ }^{16}$ and the combination of conditions was intended to cover the most relevant services offered by hospitals - that is, emergency surgical and medical services, and maternal and neonatal services. The limitation to three conditions (acute myocardial infarctions (AMI), acute appendicitis and deliveries) was to allow for more specific and more detailed data collection. In all, 199 items were included in the questionnaire; all but one were closed questions. Answer categories varied from a two-point to a five-point scale, depending on the type of question. The development of the questionnaire is described in detail elsewhere. ${ }^{6}$

\section{Participation}

The countries participating in this study were Spain, France, Poland, Czech Republic, the UK, Ireland, Belgium, and the Netherlands. In all, 483 acute care hospitals located in these eight EU member states visited the online questionnaire, and ultimately 389 returned a completed questionnaire. The resulting study population consisted of public (80\%) and private $(20 \%)$ hospitals, and included university (23.5\%), teaching (48.9\%), and non-teaching settings (276\%). More detailed information on sampling, recruitment and participation is available elsewhere in this supplement. ${ }^{6}$

\section{Design of the quality improvement maturity index}

As described briefly above, our web-based questionnaire elaborated on previous research ${ }^{3-11}$ in the field of $\mathrm{OI}$ and management. To define the maturity of a hospital OI system (ie, the total of all OI activities performed), we developed a classification model named the quality improvement maturity index based on a selection of items listed in section 1 of the questionnaire, which dealt with hospital-wide policies, procedures, and activities. The OI maturity index consisted of seven domains, totalling 113 items from section 1 of the questionnaire:

1. policy, planning, documents (20 items);

2. leadership (36 items);

3. structure (19 items);

4. general OI activities (8 items);

5. specific OI activities (20 items);

6. patient involvement (6 items);

7. accountability (4 items).

These domains were constructed based on conceptual assumptions, including information from the general part of the questionnaire, and elaborating in part upon previous work by others. ${ }^{37}$ Individual items were coded on a four-point scale ranging from 1 (most mature) to 4 (least mature). For items in the questionnaire that used a four-point answer scale (for example: $1=$ yes always, $2=$ most of the time, $3=$ sometimes, $4=$ no) the answers could be easily transposed in terms of maturity level, since a lower score already indicated a more favourable answer. However, items using a two-point scale (yes/no) needed to be recoded to fit the four-level maturity index. The recoding procedure for these items was based on the four stages of the quality cycle: plan, do, check and act. All negative answers (ie, answer =no) were recoded as 4. A positive answer (yes) was assigned a weight based on the principles of the plan-do-check-act cycle, and accordingly recoded as OI maturity level 1-3 (see table 1).

To illustrate the nature of the items included, box 1 describes in more detail one of the domains: OI activities. Previous research by Wagner and colleagues yielded a similar domain, ${ }^{37}$ since their work was used to design our web-based questionnaire and to formulate the maturity index domains.

\section{Statistics}

The conceptual assumptions underlying the seven domains were globally assessed for each domain separately by factor analysis (principal component analysis, oblimin procedure, forced one-factor solution to determine whether factor loadings globally confirmed the assignment of items to the previously formulated domains), and based on internal consistency reliability (Cronbach $\alpha$ ). However, since in this stage of the

Box 1: Illustration of the construction of one of the seven maturity index domains

\section{Questions included in the quality improvement activities domain}

Which of the following internal quality improvement activities take place in your hospital?

- Quality improvement teams or circles

- Internal audit

- Adverse event reporting and analysis

- Risk management and patient safety

- Patient surveys

- Analysis of patient complaints

- Monitoring the views of referring professionals

- Regular staff performance reviews

Answers are scored on a four-point scale:

$1=$ Yes, this activity takes place systematically in most departments (>50\%).

$2=$ Yes, this activity takes place in most departments (>50\%), but not systematically.

$3=$ Yes, this activity takes place in some departments $(<50 \%)$. $4=$ No, this activity does not take place 
analysis our main aim was to classify hospitals based on the items selected previously, these results were not used to adjust the domains by excluding items with low factor loadings or items resulting in a higher Cronbach $\alpha$.

Mean summary scores per domain were computed when the data for at least half of the items were available, or half plus one in the case of uneven numbers. These seven domain mean scores were combined in a mean overall score per hospital, which expressed the institution's OI maturity level on a scale from 1 (most mature QI system) to 4 (least mature OI system). Again, a requirement for this computation was that data for at least half of the domains had to be available. To further explore the robustness of the OI maturity index, we calculated correlations between the domains (Spearman $\rho$ ) as well as the correlation of each domain with the overall OI maturity classification. To validate the OI maturity index, three independent analyses were performed: hypothesis testing; on-site hospital visits; and expert assessment of the maturity of the QI system based on written information.

\section{Hypothesis testing}

In order to check the validity of our classification scheme, hypothesis testing was done with the self-reported data set to analyse the extremes of the maturity classification-that is, hospitals with the most mature versus least mature OI systems. We tested the relation between OI maturity and selected outputs such as external pressure, compliance with safety requirements and compliance with support of cross-border patients. These outputs were defined by combining items from section 1 of the questionnaire ${ }^{6}$ into a summary score. With the exception of one item, these items were scored on a two-point scale as yes or no, ${ }^{6}$ with lower scores reflecting better outputs. External pressure consisted of nine items:

- use of International Organization for Standardization (ISO) standards;

- European Foundation for Quality Management (EFOM) model for implementing OI strategies;

- external assessment in the preceding 3 years;

- use of peer review (ie, site visits);

- external audit of five laboratories:

- clinical chemistry;

- pathology;

- microbiology;

- pharmacy;

- diagnostic radiology.

The compliance with safety requirements output consisted of four items:

- standardised, limited number of drugs or a formulary for medications;

- electronic drug prescription system;

- a system for patient identification with bracelets in the emergency department;

- system for patient identification with bracelets for admitted patients.

Lastly, compliance with the support for cross-border patients output included six items:

- formalised arrangement with a translation service for EU patients;

- information leaflets in the other EU languages;

- provision of a case manager for non-native speaking patients;
- one or more designated persons to support foreign EU patients in administrative procedures such as payment or transportation;

- procedure defining how the hospital offers assistance to foreign EU patients in seeking contact with family or friends;

- procedure defining how the hospital offers assistance to foreign EU patients in seeking contact with their family doctor or general practitioner.

Further, to check the association between OI maturity and the service-specific sections of the questionnaire, we tested the use of two performance indicators for the management of AMI patients (section 2 of the questionnaire) - for example, availability in the hospital of the door-to-needle time indicator, and availability of the "use of aspirin within 24 h of AMI diagnosis" indicator. ${ }^{6}$

\section{Hospital on-site assessment}

Experienced, trained independent external surveyors conducted visits to a selected sample of 89 hospitals that were classified on the basis of their completed questionnaire as having most mature or least mature OI systems. External surveyors were blinded to both the classification status of the hospitals and their questionnaire results. After on-site assessment, the surveyors graded the hospitals from 1 (least developed OI system) to 5 (most developed OI system) based on their own knowledge of hospital OI systems. These grades were compared with the OI maturity index classification using cumulative logit random models. The surveyors also drafted a report for each hospital that included a descriptive summary of the most relevant information, as well as the hospital's main strengths and weaknesses. The hospital on-site assessment is described in detail elsewhere. ${ }^{19}$

\section{Expert assessment of quality improvement system maturity}

The reports drafted by the on-site surveyors were analysed by an internationally recognised expert in external quality assessment who classified the hospitals as most mature and least mature based on that information. This expert was blinded to the results of the maturity index classification. The level of agreement between this classification and the maturity index classification was calculated with $\kappa$ statistics.

\section{RESULTS}

\section{Statistics}

Of the 389 hospitals who responded to the questionnaire, 349 provided enough data to calculate the OI maturity classification. The results of forced one-factor analysis (not shown)

Table 2 Construction of the quality improvement (0I) maturity index in seven domains and 113 items

\begin{tabular}{lcl}
\hline Domain & $\begin{array}{l}\text { Number of items } \\
\text { included }\end{array}$ & Cronbach $\boldsymbol{\alpha}$ \\
\hline $\begin{array}{l}\text { Policy, planning, } \\
\text { documents }\end{array}$ & 20 & 0.86 \\
Leadership & 36 & 0.89 \\
Structure & 19 & 0.69 \\
Ol activities & 8 & 0.75 \\
Ol activities & 20 & 0.85 \\
(laboratories) & & \\
Patient involvement & 6 & 0.82 \\
Accountability & 4 & 0.54 \\
Total & 113 & 0.72 \\
\hline
\end{tabular}


Table 3 Correlations (Spearman $\rho$ ) between the domains of the quality improvement (O्l) maturity index, and between other domains and the index

\begin{tabular}{|c|c|c|c|c|c|c|c|c|}
\hline & Policy & Leadership & Structure & ol activities & $\begin{array}{l}\text { OI activities } \\
\text { (laboratories) }\end{array}$ & Patient involvement & Accountability & ol maturity index \\
\hline Leadership & $0.469 *$ & 1.0 & & & & & & $0.686^{*}$ \\
\hline Ol activities & $0.564^{*}$ & $0.489 *$ & $0.515^{*}$ & 1.0 & & & & $0.766^{*}$ \\
\hline Ol activities (laboratories) & $0.516^{*}$ & $0.304^{*}$ & $0.499^{*}$ & $0.478^{*}$ & 1.0 & & & $0.615^{*}$ \\
\hline Patient involvement & $0.20^{*}$ & 0.108 & $0.215^{*}$ & $0.242^{*}$ & -0.025 & 1.0 & & $0.402^{*}$ \\
\hline
\end{tabular}

${ }^{*} p=0.01$.

showed low $(<0.30)$ to relatively high $(0.82)$ factor loadings, indicating that the domains will require further adjustment and refinement in order to develop our QI maturity classification into a robust instrument.

Internal consistency of the domains was reasonable (Cronbach $\alpha=0.69$ ) to good (Cronbach $\alpha=0.89$ ), except for the accountability domain (table 2). For conceptual reasons, however, it was decided to maintain the latter domain in the maturity index. For the combined OI maturity index the Cronbach $\alpha$ was 0.72 (table 2).

Significant correlations between the different domains was found. Most correlations were statistically significant at the $p=0.01$ level (table 3). All correlations were $<0.70$, indicating that independent aspects were captured by the different domains, except for the correlation between the structure and policy domains, with a correlation of 0.730 . Table 3 also shows that all seven domains had notable correlations with the overall QI maturity classification. This means that all domains contributed to the maturity classification; however, the strength of the relationships varied from 0.402 (patient involvement) to 0.766 (OI activities), indicating that further research and development to refine the weightings of the domains might be appropriate.

\section{Classification of hospitals}

Table 4 summarises the variance in the mean overall OI maturity index score for participating countries. The UK and the Netherlands had lower maximum scores (meaning more mature OI systems) than other countries, but this may have been due to the lower numbers of hospitals from these countries that participated in this study.

For the entire sample we categorised hospitals according to their OI maturity level as most mature $(\leqslant 25$ th percentile; $\mathrm{n}=87$ ), intermediate $(>25$ th percentile to 75 th percentile; $\mathrm{n}=175)$, or least mature $(>75$ th percentile; $\mathrm{n}=87)$. With the exception of the UK and the Netherlands, least mature hospitals were found in all countries, and all countries also had most mature hospitals (table 4).

\section{Validation}

\section{Hypothesis testing}

The validity of the maturity classification was further explored by analysing the two extreme groups through selected hypothesis testing. Table 5 shows that hospitals with more mature OI systems performed better in all but one of the hypotheses (AMI indicator, aspirin use started within $24 \mathrm{~h}$ after AMI).

\section{Hospital site visits and assessment}

Table 6 shows the hospital ratings provided by external surveyors. The cumulative logit random effects model showed that hospitals classified as most mature according to the OI maturity index received higher grades, whereas hospitals classified as least according to the OI maturity classification were given worse grades. The odds that the grade would fall below any given category for least mature hospitals were 30.77 fold (95\% CI 6.03 to 160.32), the estimated odds for most mature hospitals.

Expert assessment of quality improvement system maturity Complete hospital reports were written for 38 of the 89 hospitals that were externally assessed by independent surveyors. The other 51 reports did not include $(n=27)$, or only partially included $(n=24)$ the requested summary of main findings, and thus could not be used by the external expert to classify the maturity of the hospitals' OI systems. Classification by the external expert of the 38 hospitals that were included in

Table 4 Variance in overall quality improvement maturity classification scores, and distribution of scores

\begin{tabular}{|c|c|c|c|c|c|}
\hline \multirow[b]{2}{*}{ Country } & \multicolumn{2}{|c|}{$\begin{array}{l}\text { Variance in maturity } \\
\text { classification score* }\end{array}$} & \multicolumn{3}{|c|}{ Maturity classification scores (based on quartiles) } \\
\hline & Min score & Max score & $\begin{array}{l}\text { Most mature } \\
(\leqslant 25 \%)\end{array}$ & $\begin{array}{l}\text { Intermediate } \\
\text { maturity } \\
(>25 \%-75 \%)\end{array}$ & $\begin{array}{l}\text { Least mature } \\
(>75 \%)\end{array}$ \\
\hline Belgium $(n=24)$ & 2.10 & 3.10 & 3 & 16 & 5 \\
\hline Czech Republic $(\mathrm{n}=38)$ & 1.50 & 3.00 & 10 & 22 & 8 \\
\hline France $(n=65)$ & 1.87 & 3.25 & 11 & 32 & 22 \\
\hline Ireland $(n=23)$ & 1.90 & 3.08 & 8 & 12 & 3 \\
\hline The Netherlands $(n=8)$ & 2.09 & 2.52 & 4 & 4 & - \\
\hline Poland $(n=76)$ & 1.86 & 3.45 & 22 & 33 & 21 \\
\hline Spain $(n=105)$ & 1.70 & 3.26 & 20 & 55 & 30 \\
\hline UK $(n=10)$ & 1.77 & 2.37 & 9 & 1 & - \\
\hline Total $(n=349)$ & 1.50 & 3.45 & 87 & 175 & 87 \\
\hline
\end{tabular}

\footnotetext{
* Low scores reflect higher maturity.
} 
Table 5 Validation of the quality improvement maturity index through hypotheses testing

\begin{tabular}{|c|c|c|c|c|c|}
\hline \multirow{2}{*}{$\begin{array}{l}\text { Hypotheses tested: output } \\
\text { was related with maturity of } \\
\text { the hospital's 0l system }\end{array}$} & \multicolumn{2}{|c|}{ Operationalisation of values tested } & \multicolumn{3}{|c|}{ Distribution of ol maturity classification (mean scores) } \\
\hline & $\begin{array}{l}\text { Number of items included } \\
\text { (Cronbach } \alpha ; \mathrm{n} \text { ) }\end{array}$ & Significant at $p$ level & $\begin{array}{l}\text { Most mature } \\
(\leqslant 25 \%)\end{array}$ & $\begin{array}{l}\text { Least mature } \\
(>75 \%)\end{array}$ & Total \\
\hline External pressure & $9(0.68 ; n=126)$ & $<0.001$ & $1.71(n=78)$ & $2.75(n=76)$ & $2.25(n=310)$ \\
\hline \multirow[t]{2}{*}{$\begin{array}{l}\text { Support for cross-border care } \\
\text { patients }\end{array}$} & $6(0.61 ; n=298)$ & $<0.001$ & $1.60(n=86)$ & $1.76(n=84)$ & $1.96(n=346)$ \\
\hline & & & \multicolumn{3}{|c|}{ Distribution of quality improvement maturity classification (\%) } \\
\hline $\begin{array}{l}\text { Availability of AMI indicator: } \\
\text { aspirin }<24 \text { h after AMl: } \% \\
\text { yes }\end{array}$ & 1 & 0.03 & 82.4 & 64.0 & 71.4 \\
\hline
\end{tabular}

*To avoid overlap contamination in the measures and output, a modified Ol maturity index was computed excluding all items related to safety.

the analysis resulted in $76.32 \%$ agreement between the expert's hospital classification and the classification based on the maturity index. The $\kappa$ value was 0.526 (standard error $=0.128$ ); in cases in which the two evaluations disagreed, the direction of disagreement was positive in $89 \%$.

\section{DISCUSSION}

We constructed a OI maturity index for a sample of European hospitals. The maturity index was found to be useful to differentiate between hospitals according to the maturity of their QI system, defined as the total of OI activities performed. The results of independent analyses sustain the validity of the OI maturity index in our research sample.

Clearly, hospitals with the most mature OI systems were identified in all participating countries. This is in line with a previous MARQuIS study report in which we found that OI strategies were widely applied in all participating European countries. ${ }^{17}$ Considerable variation in the maturity of hospital OI systems was identified both within and between countries, and it is interesting to note that variation within countries seemed to be as high as variation between countries. In future research multilevel analyses may be indicated to unravel the underlying causes of variability within and between countries. It should be stressed that hospitals classified as most mature do not necessarily deliver the best quality care to their patients. However, the hypotheses that we tested to validate the maturity index indicated that maturity of a hospital's OI system may be positively associated with better outputs.

This study has its limitations. Although data from the questionnaire were self-reported, it has been shown through onsite visits that they seemed to be fairly reliable. Furthermore,

Table 6 Agreement between quality improvement (0I) maturity index classification and assessments of independent surveyors*

\begin{tabular}{llc}
\hline Evaluator scale & $\begin{array}{l}\text { Least mature } \\
\mathbf{n}(\%)\end{array}$ & $\begin{array}{l}\text { Most mature } \\
\mathbf{n}(\%)\end{array}$ \\
\hline Least developed Ol & $11(84.6)$ & $2(15.4)$ \\
& $18(85.7)$ & $3(14.3)$ \\
Intermediate & $13(46.4)$ & $15(53.6)$ \\
& $10(25.0)$ & $30(75.0)$ \\
Most developed OI & 0 & $6(100)$ \\
Total & $52(48.1)$ & $56(51.9)$ \\
\hline
\end{tabular}

*In general, two surveyors audited each hospital. Their responses were included independently in the analysis (either both gave the same response, or each gave a different one). Some hospitals were audited by only one surveyor, and not all of them provided a maturity rating. selection bias among participating hospitals cannot be ruled out. Although hospitals were sampled randomly, the results need to be interpreted with some caution in terms of generalisability, given the different response rates between countries. Especially in countries with low response rates, participating hospitals might comprise a selected group.

The present results are too preliminary to validate the proposed OI maturity scheme as an instrument. Our purpose was to classify hospitals in our sample for further analyses within the project according to their level of OI. Therefore we developed a scheme based on conceptual assumptions regarding OI in hospitals, and evaluated the sustainability of these assumptions statistically. Some of the results supported the concept of our maturity scheme, whereas others might be arguable from a psychometric point of view-for example, the high number of items, the very high Cronbach $\alpha$ for domains that were measured with large numbers of questionnaire items (eg, leadership), and the relatively low Cronbach $\alpha$ for accountability. However, the three independent validation analyses provide additional support for the validity of the classification scheme in our research sample.

It seems worthwhile to develop the current classification scheme further, into an instrument that can be used as a practical "quick scan" to assess the maturity of hospital OI systems. Once in place, it may help healthcare leaders at both the policy and the hospital level to identify areas on which to focus for further implementation of OI strategies. Bearing this in mind, further development of the maturity index classification into an instrument will require additional exploration and analyses of the MARQuIS study data to confirm our preliminary findings. Such analyses should include at least three actions. First, the maturity index should be simplified by deleting some items. Further statistical analysis would help to indicate which items discriminate least. Second, weighting of the domains requires further refinement. The domains that contribute to the overall maturity index should be identified, and their contributions should be translated into weightings that take into consideration issues such as the number of items to be included, among other aspects. Third, further reliability testing should be performed by applying the OI maturity index to other data sets.

\section{CONCLUSION}

The proposed classification scheme, called here the maturity index, was useful in differentiating between hospitals in our research sample according to the maturity of their QI system, defined as the total of all OI activities. The validity of the results 
for our sample was supported by three different types of analysis. Further research is recommended to develop this scheme into an instrument that can be used as a practical "quick scan" to assess the maturity of hospital quality improvement systems.

Acknowledgements: The authors thank the European Commission for funding this research, and all those who have supported and guided this work both within the MARQulS project team and as external associates. In particular, we thank all country coordinators for their valuable comments: B Kutryba (Poland), J Bañeres (Spain), P Doets and $\mathrm{H}$ Beaard, (the Netherlands), C Bruneau and F Bousquet (France), A Jacquerye and A Vleugels (Belgium), I Stanek, S Zamarian and V Typovska (Czech Republic), H Crisp and A Cassell (UK), and E O'Connor (Ireland). Lastly, we thank all the MARQulS research and project partners for their continuing collaboration in this part of the study: B van Beek, P Garel, 0 Groene, K Hanslik, P Poletti, C Shaw, E Spencer and $\mathrm{K}$ Walshe.

Funding: Research done for the "Methods of Assessing Response to Quality Improvement Strategies (MARQuIS)" project (SP21-CT-2004-513712) was funded by the European Commission through its Scientific Support to Policies action under the Sixth Framework Programme for Research.

Competing interests: None.

\section{REFERENCES}

1. Klazinga NS. Concerted action programme on quality assurance in hospitals 19901993 (COMAC/HSR/QA). Global results of the evaluation. Int J Qual Health Care 1994;6:219-30.

2. Shaw CD. External quality mechanisms for health care: summary of the ExPeRT project on visitatie, accreditation, EFOM and ISO assessment in European Union countries. Int J Qual Health Care 2000;12:169-75.

3. Wagner C, De Bakker DH, Groenewegen PP. A measuring instrument for evaluation of quality systems. Int J Qual Health Care 1999;11:119-30.

4. Silimperi DR, Franco LM, Veldhuyzen van Zanten T, et al. A framework for institutionalizing quality assurance. Int J Qual Health Care 2002;14S:67-73
5. Meurer SJ, McGartland Rubio D, Counte MA, et al. Development of healthcare quality improvement measurement tool: results of a content validity study. Hospital Topics 2002;80:7-13.

6. Lombarts MJMH, Rupp I, Vallejo P, et al. Application of quality improvement strategies in 389 European hospitals: results of the MARQulS project. Qual Safety Health Care 2009;18(Suppl I):i28-37.

7. Wagner C, Gulácsi L, Takacs E, etal. The implementation of quality management systems in hospitals: a comparison between three countries. BMC Health Serv Res 2006;6:50

8. Groene 0, Jorgensen SJ. Health promotion in hospitals: a strategy to improve quality in health care. Eur J Pub Health 2005;15:6-8.

9. WHO Europe. Standards for health Promotion in Hospitals. Self-assessment Tool for pilot implementation. Geneva: WHO, 2004.

10. Shortell S. Implementation survey II, Ouality management section. Berkeley, CA, USA: Health Policy and Management, School of Public Health, University of California, 1992.

11. Ovretveit J. What are the best strategies for ensuring quality in hospitals? Geneva: WHO-HEN, 2003.

12. WHO/ISQuA. Quality and accreditation in health care services. A global review. Evidence and Information for Policy, Department of Health Service Provision. Geneva: World Health Organization, 2003.

13. Franco LM, Silimperi DR, Veldhuyzen van Zanten T, et al. Sustaining quality of healthcare: institutionalization of quality assurance. Bethesda, MD: Center for Human Services, Quality Assurance Project, 2002, Sept:viii, 52 (OA monograph/USAID Contract No. HRN-C-00-96-90013).

14. Avedis Donabedian Foundation, Spain; Health Quality Service, UK. Analysis of main contents on European Accreditation systems. Scientific support report I, Feb 2005. MARQulS project. Spain: Avedis Donabedian Foundation, 2005.

15. Joint Commission International. JCl accreditation standards for hospitals Chicago, IL: Joint Commission, 2003.

16. Suñol R, Garel P, Jacquerye A et al. Cross-border care and healthcare quality improvement in Europe: the MARQulS research project. Qual Saf Health Care 2009;:XX (Suppl X):XXX-XXX

17. Spencer $\mathbf{E}$, Walshe K. National quality improvement policies and strategies in European healthcare systems. Qual Saf Health Care 2009;18(Suppl I):i22-7.

18. Groene 0, Poletti $\mathrm{P}$, Vallejo $\mathrm{P}$, et al. Quality requirements for cross-border care in Europe: a qualitative study of patients', professionals' and healthcare financiers' views. Qual Saf Health Care 2009;18(Suppl I):i15-21.

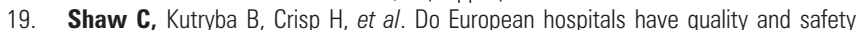
governance systems and structures in place? Qual Saf Health Care 2009;18(Suppl I):i51-6. 